\title{
THE PROSODIC ANALYSIS OF KOREAN DIALOGUE SPEECH - THROUGH A COMPARATIVE STUDY WITH READ SPEECH -
}

\author{
Cheol-jae Seong and Minsoo Hahn \\ Spoken Language Processing Section \\ Electronics \& Telecommunications Research Institute \\ 161 Kajong-Dong, Yusong-Goo, \\ Taejon, 305-350, KOREA \\ scj@zenith.etri.re.kr / mshahn@audio.etri.re.kr
}

\begin{abstract}
This paper describes the prosodic features of Korean dialogue speech. With 25 sentences for scheduling, one speaker uttered in two manners, viz. 'read' and 'dialogue'. The main discriminating features would be some aspects in speech rate and boundary signal. We discriminated each prosodic phrase in a sentence to investigate pre-boundary, boundary, and post-boundary features. The durational aspect in dialogue speech shows much more drastic characteristics than that in read. We can see that the boundary syllables of dialogue seem to be 2.3 times longer than that in preboundary syllable. The final syllables are about 1.7 times longer than prefinal syllables.

Pitch analysis shows that dialogues are pronounced $14.3 \%$ higher than read. Emotional factor of dialogue seems to raise the average pitch. It was interesting that the minimum pitch values are about $72 \%$ of sentential mean for both similarly. In dialogue, there was great difference between the pitch of prefinal and that of final syllable, i.e., the final syllables are almost $15 \%$ higher.

The results confirms our general ideas that 1) the duration is more dynamic in dialogue than in read speech, 2) pitch contour fluctuation is larger in dialogue than in read speech, 3) dialogue is usually uttered in higher tone, 4) and sentential final part may play an decisive role in speech style determination.
\end{abstract}

\section{INTRODUCTION}

This study aims to describe the prosodic features of Korean Dialogue Speech in the viewpoint of various acoustic phonetic parameters. Dialogue speech is told that it is strongly related to the spontaneous circumstance among speakers involved in communication and also tends to be uttered in rather irregular speech rate.

Accordingly, there can be no denying that the prosodic features of dialogue must be coupled with the general characteristics of its proper speech style. As everyone expects easily, dialogue speech seems to show more various speech rate, higher Fo fluctuation, and variety of accent placement in a sentence, which may be concerned with both emotional aspect of speaker and direct conversational situation. These characteristics may control the prosodic features of dialogue speech with primary importance. Our efforts was focused on duration and Fo among the main acoustic parameters.

The general characteristics of dialogue speech can be summarized as follows.

* Insertion of various interjections

* Omission

* Simplified expression

* Self-correction

* Hesitation

* Unintentional or Intentional repeating

* Expressions presenting turning point

* Floor-holding vocalization

* Disfluencies

* Filled pauses

* Dynamic variation of prosody

* Weak grammar

* Too much coarticuation

* Careless speech

* Uncontrolled speech rate - Bursts of faster \& slower section

* Much greater variation in Fo

* To have many different communicative purposes

* Topicalization - narrowly focusing

* Insertion of useless expressions

\section{EXPERIMENT}

\subsection{Material}

25 scheduling sentences, which were selected from the ETRI(Electronics and Telecommunications Research Institute) spontaneous speech corpus, were used. Each sentence does not exceed one line, more precisely, is composed of $9-26$ syllables.

\subsection{Subject}

The subject is male in his early 30 s. And he is not only well educated in Seoul area but also has a prominent talent in articulating the lab speech. 


\subsection{Procedure}

Recording was performed in sound proof room in Linguistics Department of Seoul National University. We use DAT(SONY TCD-D3) and Unidyne III 545 D dynamic microphone of Shure Inc. It was planned to speak the same sentence in two different manners, viz. 'read' and 'dialogue' styles. The subject repeated 6 times totally among which the first half was 'read style speech' and the other, dialogue. The best session from each case was finally selected, and therefore the number of resulted sentences were counted as 50 .

A/D conversion was carried out in Sparc 5 workstation under the condition of $16 \mathrm{kHz}$ sampling, 16 bit resolution. For the analysis, $8 \mathrm{msec}$ hanning window, 256 point FFT, and preemphasis coefficient of 0.94 were applied. ESPS on Xwaves was used as our analyzing tool. Using a label file in Xwaves, we measured the duration $(\mathrm{msec})$ and $\mathrm{Fo}(\mathrm{Hz})$. Fo was calculated by a process of averaging total frame value of vowel (+ sonorant) section in each syllable. Then the Statview program of Macintosh has been used for the statistical analysis.

\section{RESULT}

We think that when the same sentence is pronounced in two different manners, the main points that can discriminate each other would be some different aspects in speech rate and boundary signal. The durational aspect plays an decisive role in controlling the speech rate and the boundary signal might be comprised of durational and intonational fluctuation.

Therefore, at first, we have discriminated each prosodic phrase in each sentence to investigate the preboundary, boundary, and postboundary features. Prosodic phrase, here, means a prosodic unit which can be clearly identified as having an evident break at its final position in a sentence in the sense of perceptual viewpoint. The end of each prosodic phrase was, accordingly, marked as the point of major boundary in a sentence. We measured the duration and pitch for each unit(prosodic phrase).

\subsection{Duration}

\subsubsection{Speech Rate}

Among 25 sentences, only 5 dialogues are longer than read sentences $(20 \%)$. Average duration of dialogue speech is $90.6 \%$ of that of read speech. Approximately $83.2-87.1 \%$ radius was the largest case $(24 \%)$.

The number of resulted prosodic phrase was counted 54 in read and 55 in dialogue. In read sentences, the average duration of total prosodic phrases is $1337.285(\mathrm{sd}=529.3) \mathrm{msec}$. The same calculation gives the value of $1137.138(\mathrm{sd}=498.7) \mathrm{msec}$ in dialogue. Average syllable duration of prosodic phrase is 172.527 and $159.654 \mathrm{msec}$ in read and dialogue, respectively. Following table shows that the mode of frequency distribution radius of average duration of total prosodic phrases.

\begin{tabular}{lll}
\hline statistics & read & dialogue \\
\hline mode & $1228.7-1453.8$ & $914.6-1134.7$ \\
& $(10 / 54,18.5 \%)$ & $(12 / 55,21.8 \%)$ \\
& $1678.9-1903.9$ & $1354.9-1575$ \\
& $(11 / 54,20.4 \%)$ & $(11 / 55,20 \%)$ \\
\hline
\end{tabular}

Table 1: Distribution of average duration of total prosodic phrases in read and dialogue speech(msec).

n: number, s.d.: standard deviation, mode: mode of frequency distribution radius.

\subsubsection{Boundary Information}

42 prosodic phrases which are marked as having the same content in two different speeches are the target on which we investigate the duration of preboundary and boundary syllable. We differentiate the sentential final boundaries from the syllables of other positions for the reason of sentential final large lengthening. In Read speech, the mean duration of preboundary syllable vs. boundary syllable is $152.1: 277.5 \mathrm{msec}$. Against this, in Dialogue Speech, the same statistic is calculated as 135.2: $310.2 \mathrm{msec}$.

\begin{tabular}{|c|c|c|}
\hline statistics & read & dialogue \\
\hline \multicolumn{3}{|c|}{ preboundary syllable } \\
\hline Mean & $152.148(n=27)$ & $135.211(\mathrm{n}=27)$ \\
\hline s.d. & 51.9 & 50.3 \\
\hline $\begin{array}{l}\text { distribution } \\
\text { mode }\end{array}$ & $\begin{array}{l}130.9-151.9 \\
(\mathrm{n}=8 / 27,29.6 \%)\end{array}$ & $\begin{array}{l}107.1-161.5 \\
(\mathrm{n}=14 / 27,32 \%)\end{array}$ \\
\hline \multicolumn{3}{|c|}{ boundary syllable } \\
\hline Mean & $277.531(n=29)$ & $310.177(n=30)$ \\
\hline s.d. & 68.8 & 87.86 \\
\hline $\begin{array}{l}\text { distribution } \\
\text { mode }\end{array}$ & $\begin{array}{l}251-337 \\
(\mathrm{n}=15 / 29,51 \%)\end{array}$ & $\begin{array}{l}302.5-388.7 \\
(\mathrm{n}=12 / 30,40 \%)\end{array}$ \\
\hline
\end{tabular}

Table 2: Distribution of average duration of preboundary and boundary syllable in read and dialogue speech(msec). $\mathrm{n}$ : number, s.d.: standard deviation, mode: mode of frequency distribution radius.

At sentential final position, the mean duration of preboundary(prefinal) vs. boundary(final) syllable is 132.28( $\mathrm{n}=25, \mathrm{sd}=40.57): 237.084(\mathrm{n}=25, \mathrm{sd}=40.57) \mathrm{msec}$ in read speech. In dialogue, it is resulted as $119.252(\mathrm{n}=25, \mathrm{sd}=53.1)$ : $211.336(\mathrm{n}=25, \mathrm{sd}=43.3) \mathrm{msec}$. The mode of frequency distribution radius about this statistic is presented by following table(Table 3).

\begin{tabular}{lll}
\hline statistics & read & dialogue \\
\hline prefinal & $54.2-102.2$ & $61.2-102.56$ \\
& $(\mathrm{n}=11 / 25,44 \%)$ & $(\mathrm{n}=11 / 25,48 \%)$ \\
final & $\begin{array}{l}224.6-256.6 \\
(\mathrm{n}=11 / 25,44 \%)\end{array}$ & $\begin{array}{l}215.98-230.96 \\
(\mathrm{n}=5 / 25,20 \%)\end{array}$ \\
\hline
\end{tabular}


Table 3: Mode of frequency distribution of Average duration of prefinal and final syllable in read and dialogue $\operatorname{speech}(\mathrm{msec}) \cdot \mathrm{n}=$ number.

\subsection{Pitch}

\subsubsection{Average Value of Total Sentence}

The average Fo of total sentences in read speech is 103.724( $\mathrm{n}=25, \mathrm{sd}=3.4) \mathrm{Hz}$. In dialogue, it is $118.548(\mathrm{n}=25$, $\mathrm{sd}=6.84) \mathrm{Hz}$. Hence the average of differences between read and dialogue is $14.824(n=25$, s.d. $=4.9) \mathrm{Hz}$, and that means dialogue sentences are pronounced $14.3 \%$ higher than read, in general.

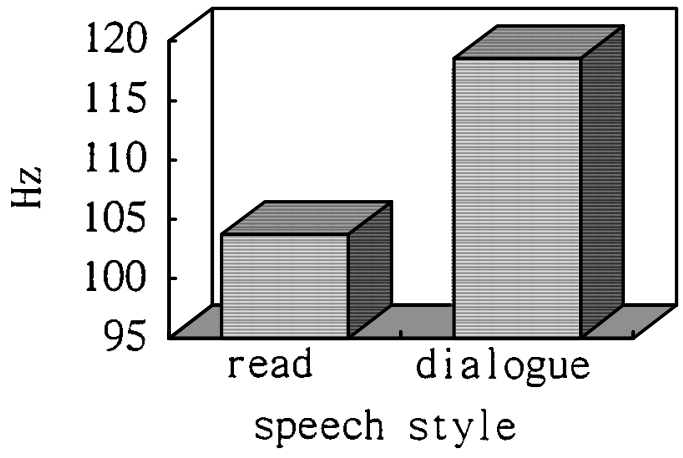

Figure 1: The average Fo of total sentences in read and dialogue $\operatorname{speech}(\mathrm{Hz})$.

\subsubsection{Average Maximum and Minimum Value of Total Sentences}

The average maximum pitch of sentential syllables is about 27.7 and $35 \%$ higher than the sentential mean pitch values in read and dialogue speech, respectively(max in read. $=132.4 \mathrm{~Hz}, \mathrm{n}: 25$, sd: $8.86 /$ max. in dialogue $=159.96 \mathrm{~Hz}, \mathrm{n}: 25$, sd: 14.7). The average minimum pitch extends to about $72 \%$ of sentential mean values for both styles $(\mathrm{min}$. in read $=76.56 \mathrm{~Hz}, \mathrm{n}: 25, \mathrm{sd}=$ $6.25 / \mathrm{min}$. in dialogue $=85.04 \mathrm{~Hz}, \mathrm{n}=25, \mathrm{sd}=5.56$ ).

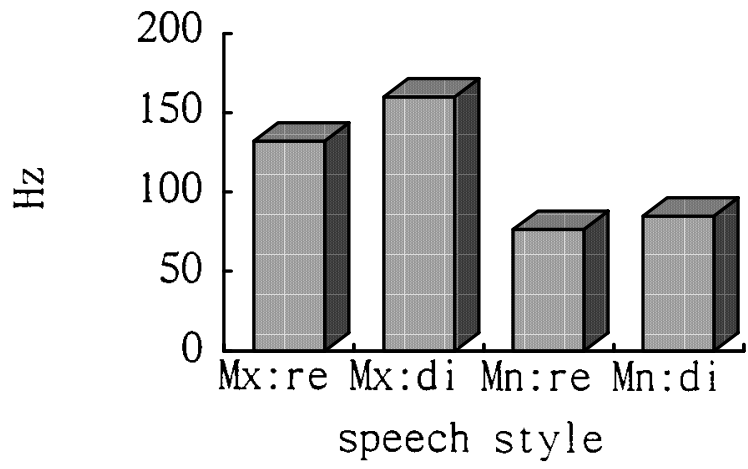

Figure 2: Average maximum and minimum pitch of sentential syllables in read and dialogue speech.

\subsubsection{Preboundary, Boundary and Postboundary Syllables}

In table 4 and 5 , we can see that the pitch of preboundary syllable in dialogue is much higher than that in read speech. Here, the mode of frequency distribution should be regarded as primary factor since all syllables were collected as the target for measurement in unified way regardless of their types. Statistical average, therefore, doesn't seem to have any impotrant meaning.

\begin{tabular}{|c|c|c|c|}
\hline statistic & preb. syl & bound. syl. & postb. syl. \\
\hline${ }_{\mathrm{n}=2}^{\text {mean }}$ & $\begin{array}{r}99.27 \mathrm{~Hz} \\
26, \mathrm{sd}=8.8\end{array}$ & $\begin{array}{c}100 \mathrm{~Hz} \\
\mathrm{n}=29, \mathrm{sd}=12.8\end{array}$ & $\begin{array}{c}98.38 \mathrm{~Hz} \\
\mathrm{n}=29, \mathrm{sd}=12.2\end{array}$ \\
\hline mode & $\begin{array}{c}94-97.5 \mathrm{~Hz} \\
\mathrm{n}=9 / 26, \quad 34.6\end{array}$ & $\begin{array}{cr} & 91.8-97.2 \mathrm{~Hz} \\
\% & \mathrm{n}=8 / 29,27.6\end{array}$ & $\begin{array}{r}97.2-103.4 \mathrm{~Hz} \\
\% \quad \mathrm{n}=11 / 29 \text {, }\end{array}$ \\
\hline
\end{tabular}

Table 4: Distribution of pitch values at preboundary, boundary, and postboundary syllables in read speech. $n=$ number, $\mathrm{sd}=$ standard deviation, mode $=$ mode of frequency distribution radius.

\begin{tabular}{|c|c|c|}
\hline preb. syl & bound. syl. & postb. syl. \\
\hline $\begin{array}{l}\text { mean } \begin{array}{l}120.12 \mathrm{~Hz} \\
\mathrm{n}=26, \mathrm{sd}=16.58\end{array}\end{array}$ & $\begin{array}{l}119.69 \mathrm{~Hz} \\
\mathrm{n}=29, \mathrm{sd}=17.01\end{array}$ & $\begin{array}{l}116.01 \mathrm{~Hz} \\
\mathrm{n}=29, \mathrm{sd}=17.57\end{array}$ \\
\hline $\begin{aligned} & \text { mode } 108-122 \mathrm{~Hz} \\
& \mathrm{n}=10 / 26,38 \%\end{aligned}$ & $\begin{array}{c}102.6-109.4 \mathrm{~Hz} \\
\mathrm{n}=7 / 29,24.1 \%\end{array}$ & $\begin{array}{c}107.2-114.6 \mathrm{~Hz} \\
\mathrm{n}=9 / 29,31 \%\end{array}$ \\
\hline
\end{tabular}

Table 5: Distribution of pitch values at preboundary, boundary, and postboundary syllables in dialogue speech. $n=$ number, $\mathrm{sd}=$ standard deviation, mode=mode of frequency distribution radius.

By the way, when we investigate the pitch difference of both between preboundary and boundary, and between boundary and postboundary, $53.8(14 / 26)$ and $44.8 \%$ of preboundary and postboundary syllables were lower than boundary syllables respectively in read speech. In dialogue, they became $53.8(14 / 26)$ and 58.6(17/29) \%. These results show that boundary syllables are slightly higher than preboundary syllables in both styles and the postboundary syllables in dialogue are started with comparatively lower tones than those in read.

In sentential final position of read speech, the mean values of preboundary and boundary syllables are $80.52(\mathrm{n}=25, \mathrm{sd}=3.917)$ and $80.28(\mathrm{n}=25, \mathrm{sd}=4.686) \mathrm{Hz}$, but in preboundary syllables, the mode of distribution radius ranges from 73 to $89 \mathrm{~Hz}$. Dialogue speech shows that final syllables are $15 \%$ higher than prefinal syllables as the value of $98.52 \mathrm{~Hz}(\mathrm{n}=25, \mathrm{sd}=10.94)$ vs. $85.48 \mathrm{~Hz}(\mathrm{n}=25, \mathrm{sd}=6.804)$. In final syllables, the frequency mode covers $87-100.2 \mathrm{~Hz}$ radius $(\mathrm{n}=19 / 25,76 \%)$, and in prefinal , 78.6-86.4 $\mathrm{Hz}$ radius $(\mathrm{n}=15 / 25,60 \%)$. 


\section{DISCUSSION}

The durational aspect in dialogue speech shows much more drastic characteristics than that in read. From Table 2, we can see that the boundary syllables of dialogue seem to be 2.3 times longer than that in preboundary and the relative shortness of preboundary syllable makes it easy to perceive the boundary syllable as longer one.

At sentential final position, the duration of both prefinal and final syllables in read is longer than those in dialogue speech. The duration ratio of prefinal to final syllables is similar in both read and dialogue speech. The final syllables are about 1.7 times longer than prefinal syllables.

Pitch analysis shows that dialogues are pronounced $14.3 \%$ higher than read in average. Emotional factor of dialogue seems to raise the average pitch. It was interesting that the minimum pitch values cover about $72 \%$ of sentential mean for both, similarly.

From the distribution of pitch values around boundary syllables in sentence medial position we can see that boundary syllables are somewhat higher than preboundary syllables in both styles and the postboundary syllables in dialogue have a tendency of being lowered compared with those in read.

In sentential final position, we can describe that the mean pitch of prefinal and final syllable was resulted in 80.52 and $80.28 \mathrm{~Hz}$, respectively, in read speech, but as observed from above, the prefinal syllables were distributed from $73-89 \mathrm{~Hz}$, i.e., comparatively widely distributed than final syllables. In dialogue, there was great difference between the two, of which the final syllables are almost $15 \%$ higher.

\section{CONCLUSION}

We described the prosodic differences between read and dialogue speech using the notion of prosodic phrase and boundary signal. Especially durational and intonational aspects were handled with primary importance.

Although there were several approaches available for analyzing the differences of the two styles, there still may remain a lot of aspects to be defined and described with respect to syntactic and semantic viewpoint.

The acoustically prominent parts of sentences or each prosodic phrase may be coupled with major grammatical functions in the target sentence, which also will be played an important role for the modeling of the duration and intonation in the future works.

The presented results reconfirms our general ideas that 1) the duration is more dynamic in dialogue than in read speech, 2) pitch contour fluctuation is larger in dialogue than in read speech 3 ) dialogue is usually uttered in higher tone, and 4) sentential final part may play an decisive role in speech style determination.

\section{REFERENCES}

1. Seong, C.J., Experimental Phonetic Study of Korean Speech Rhythm, Ph.D. dissertation in Seoul National University, 1995.

2. Mariani, J., "Speech in the context of Human-Machine Communication", Proceedings of International Symposium on Spoken Dialogue-93, International Conference Center, Waseda University, pp 91 - 94, 1993.

3. Beckman, M., "A Typology of Spontaneous Speech", Proceedings of International Workshop on Computational Modeling of Prosody for Spontaneous Speech Processing, ATR Interpreting Telecommunications Research Laboratories, Kyoto, pp 2: 23-34, 1995.

4. Campbell, N., "Automatic Detection of Prosodic Boundaries in Speech", Speech Communication 13, pp 343-354, 1993.

5. Campbell, N., "Mapping from Read Speech to Real Speech", Proceedings of International Workshop on Computational Modeling of Prosody for Spontaneous Speech Processing, ATR Interpreting Telecommunications Research Laboratories, Kyoto, pp 3: 20-25, 1995.

6. Ross, N., Modelings of Intonation for Speech Synthesis, Ph.D. dissertation, Boston University, 1995. 